INFLUENCE OF EPIDERMAL GROWTH FACTOR AND DEXAMETHASONE ON THE MATURATION OF BRUSH BORDER ENZYMIC ACTIVITIES OF THE FETAL MOUSE SMALL INTESTINE IN ORGAN CULTURE. J.-F. Beaulieu, R. Calvert, Département d'anatomie et de biologie cellulaire, Université de Sherbrooke, Sherbrooke, Quêbec, Canada (sponsored by M. R.-Pleszczynski)

We have shown that Epidermal Growth Factor (EGF) as well as dexamethasone $(\mathrm{Dx})$ exert a direct positive influence on the maturation of some brush border enzymic activities in the fetal mouse small intestine in organ culture. We report herein the effect of a combination of these two hormones. Mouse duodenal explants rea combination of these two hormones. sected at 17 days of gestation were cultured durping in Leibovitz L-15 serum-free medium alone or supplemented with
EGF $(100 \mathrm{ng} / \mathrm{ml})$ and/or $\mathrm{Dx}(300 \mathrm{ng} / \mathrm{ml})$. Maturation of absorptive cells was evaluated by measuring alkaline phosphatase (ALP), maltase (M), lactase (L), trehalase (T) and sucrase (S) activities. In control explants, protein and DNA contents and the level of the ALP, $M, T$ and $S$ specific activities remain comparable to the values measured in 17-day explants at the beginning of the culture period except for L activity that falls drastically. In explants cultured in presence of EGF and Dx, protein contents and the level of ALP, $M, T$ and $S$ activities increase significantly but only at levels comparable to those obtained with EGF or Dx separately while DNA contents remain unchanged and $\mathrm{L}$ activity remains under the level observed at the beginning of the culture period. These results suggest that EGF and glucocorticoids can influence the maturation of some brush border enzyme at a similar level in the small intestine during the fetal period.

\section{$\dagger 236$}

METABOLIC STUDIES DURING EARLY FETAL LIFE. Alan

Bell, Jan M. Kennaugh, Frederick Battaglia, Edgar $\frac{\mathrm{L}}{\text { Makowski, and Giacomo Meschia, Division of }}$ Medicine, University of Colorado School of Medicine, Denver, CO.

Previous studies of fetal metabolism were confined to the last $20 \%$ of gestation. This report presents data on 11 fetal lambs chronically catheterized at 71-81 days (mid-gestation). Mean fetal weight was $210 \pm$ $20 \mathrm{~g}$. Umbilical and uterine blood flows, and the AV differences of substrates were determined. Oxygen ( $\dot{\mathrm{V}}_{\mathrm{O}_{2}}$ ) glucose (G.U.) and lactate (L.U.) uptakes by the fetus were calculated. $\mathrm{O}_{2}$ was slightly higher (\%) expressed on a dry weight basis. Fetal G.U. was also increased relative to the term fetus but L.U. was decreased.

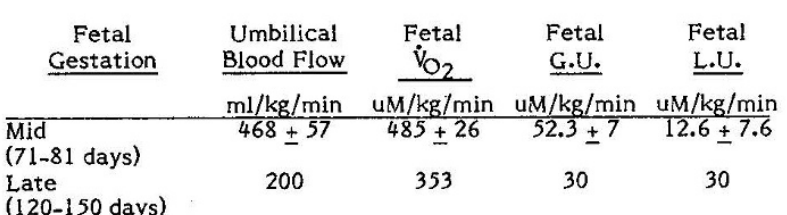

At mid-gestation placental weight is significantly greater than at term $(486+22$ vs $302+12 \mathrm{~g})$. Nevertheless, the rates of placental oxygen and glucose metabolism were significantly less than in late pregnancy and glucose metabolism were significantly less than in late pregnancy and placental lactate production was also reduced. Developmental aspects of
fetal metabolism and physiology can now be studied under unstressed steady-state conditions.

EFFECTS OF HYPOXIA ON FETAI, AND PLACENTAL

+237 GROWTH. Wm Berman, Jr., Robert Greenber

237 John Johnson. UNM, Dept Ped, Alb, NM. The effect of hypoxia (H) on fetal (F) and placental (P) growth during pregnancy was studied by placing rats in a hypobaric chamber ( $P_{\text {chamber }}=400$ torr). Ambient $\mathrm{PO}_{2}$ (torr) of control (C) animals was 123; ambient $\mathrm{PO}_{2}$ of $\mathrm{H}$ animals was 74 . All animals resided in normoxic environments for the
first 6 days of gestation. On day $7, \mathrm{H}$ animals were placed at a barometric pressure 50 torr < atmospheric: the vacuum was increased in 50 tor increments over 4 days to achieve a barometric pressure of 400 torr by day 10 of gestation (term=2l days). At 20 days, the following variables were measured for $118^{\circ} \mathrm{C}$ and $69 \mathrm{H}$ fetuses: litter size (L); F wt (gm); $P$ wt (gm); and the quantities of protein (Prot-mg), DNA and RNA (microgm) per placenta. Mean results are shown below:

\begin{tabular}{lrllllll} 
& & & & & \multicolumn{3}{c}{ Placental } \\
C & $\mathrm{L}$ & F wt & P wt & F/P & Prot & DNA & RNA \\
H & 12 & 3.74 & 0.64 & 6.67 & 48.8 & 998 & 2.0 \\
& 7 & 3.33 & 0.69 & 4.82 & 50.4 & 980 & 2.0
\end{tabular}

Hypoxia reduces $F$ wt and increases the ratio of $P / F$. Placental composition of Prot, DNA and RNA did not change. This suggests: 1) hypoxia affects fetal but not placental weight gain during pregnancy, 2) but not placental weight gain during pregnancy, 2) correlated, and 3 ) maternal circulatory adjustments to hypoxia may maintain placental weight.
RIBOFLAVIN INFLUENCE ON HEPATIC AND BRAIN RESPONSES

238 TO TRYPTOPHAN IN NEONATAL GERBILS. Jatinder Bhatia, Brown, Department of Pediatrics, University of Texas $\frac{\text { Audelio A. }}{\text { Medical }}$

Branch, Galveston, Texas.

Tryptophan ( $T$ ) photooxidized in the presence of riboflavin (R) alters hepatic function in developing animals. Solutions of $T$ $(48 \mathrm{um} / \mathrm{ml})$ were either exposed to $(+\mathrm{L})$ or protected from $(-\mathrm{L})$ light for 12 hours (in the presence, $+R$, or absence, $-R$, of $1 \mathrm{mg}$ / dl of R). Two-week old suckling gerbils were randomly assigned to daily intraperitoneal injections of $T+R+L, T+R-L, T+L, T-L$ or were untreated for $7 \mathrm{~d}\left(4 \mathrm{mM} / \mathrm{kg}^{-1} \mathrm{~d}^{-1}\right.$ of $\left.\mathrm{T}\right)$. Animals were killed on day 8 and assessed for: serum $\gamma$-glutamyl transferase; serum, liver and brain $T$ conc; body, brain \& liver weight. Data ( $\overline{\mathrm{X}} \pm S \mathrm{D})$ \begin{tabular}{lllllll}
\hline Group & $N$ & $\frac{\gamma-G T}{U / m 1}$ & $\frac{\text { Serum T }}{(\mathrm{um} / \mathrm{d} 1)}$ & $\frac{\text { Tryptophan Conc (um } / 100 \mathrm{~g})}{\text { Brain }}$ & LIver \\
\hline $\mathrm{T}+\mathrm{R}+\mathrm{L}$ & 9 & $2.19 \pm 1.07$ & $15.20 \pm 7.51$ & $10.24 \pm 3.55$ & $13.65 \pm 4.38$
\end{tabular} $\begin{array}{lllrrr}\mathrm{T}+\mathrm{R}-\mathrm{L} & 7 & 2.67 \pm 2.09 & 12.85 \pm 8.47 & 7.13 \pm 3.38 & 12.63 \pm 5.01\end{array}$ $\begin{array}{llllll}\mathrm{T}+\mathrm{L} & 8 & 0.84 \pm 0.29 & 7.38 \pm 2.18 & 3.13 \pm 0.41 & 10.91 \pm 4.53\end{array}$

$\begin{array}{llllll}\mathrm{T}-\mathrm{L} & 7 & 0.72 \pm 0.25 & 6.81 \pm 5.39 & 2.00 \pm 0.79 & 10.32 \pm 2.81 \\ \text { Untreated } & 4 & 0.62 \pm 0.03 & 7.04 \pm 1.53 & 2.36 \pm 0.39 & 5.94 \pm 0.78\end{array}$
\begin{tabular}{lll}
$2.36 \pm 0.39$ & $5.94 \pm 0.78$ \\
\hline
\end{tabular} $\gamma$-GT activity and braln conc were significantly increased in the presence or $\mathrm{R}$ and elther $+L$ or $-L$. Serum and liver concentrations of $\mathrm{T}$ were similar amongst the treatment regimens. Liver $T$ was greater in the treated animals than in those untreated.
Our data suggest the role of $\mathrm{R}$ in the alteration of hepatic function; further, both $R$ and $L$ alter brain conc of $T$ in the developing gerbil. The clinical implications of the infusion of amino acids in the presence of $R$ and $L$ must be considered.

GEAVIOURAL AND CARDIOVASCULAR GHANGRS DURTNG MECHANICAL IING

239 VENIIIATTION IN FETAL SHEEP IN UTERO. Carlos E. BlanoO', Chester B. Rigatto). 'Dept. of Pediat., Univ. of Limburg, NL. ${ }^{2}$ Dept. of ob-Gyn and ${ }^{3}$ Central Animal Laboratory, Catholic Univ., Nijnegen,

We questioned whethex the prevailing fetal PaO2 conditions the distribution and organization of states and responses in the fetus and newborn. To investigate thi we mechanically ventilated the fetal lungs in chronically instrumented fetal sheep. Electrodes (for $B C O G, B D G, B O G$ and EMG of diaphragm - DP, posterior neck and biceps brachii muscles), catheters (carotid artery, jugular vein, trachea and amiotic cavity), and the endotracheal tube and ventilator tubes were placed at 122-127 days GA. Experiments were begun 3 to 5 days later. Thus far 12 ventilation experiments have been carried out in 5 fetal sheep 3 to 13 days after operation. At the onset of mechanical ventilation both the FHR and fetal blood pressure (BP) decreased abruptly. Ventilatory arrhythria appeared and its amplitude varied inversely with frequency. During ventilation with either 02 or N2 the proportion of high voltage (HV) ECOG increased. Fetal movenents decreased during mild hypoxaenia, continuous tonic neck EMG was not observed. End-inspiratory bursts of DP EMG activity were observed more of ten during LV at nomal and elevated PaO2's and did not become continuous in either state and it varied with PaCO2. Switching abruptly to N2 after up to $4 \mathrm{~h}$ of hyperoxia did not result in stimulation of phasic DP ENG. At end of experiments $\mathrm{PaO2}$ and $\mathrm{PaCO} 2$ returned rapidly to nomal fetal levels and normal fetal state-cycling was resuned. Ooclusion of the umbilical cord with a constant flow of 02 through the tubes resulted in the initiation of sustained, continuous breathing in only one of 4 such trials.

Conclusions: 1. Mechanical ventilation appears to increase HV state. 2. Elevation of $\mathrm{PaO} 2$ does not result in 'arousal', contimuous breathing, or tonic activity in the antigravity muscles. 3. Fetal response to hypoxemia is not modified and 4. unbilical circulation renained open.

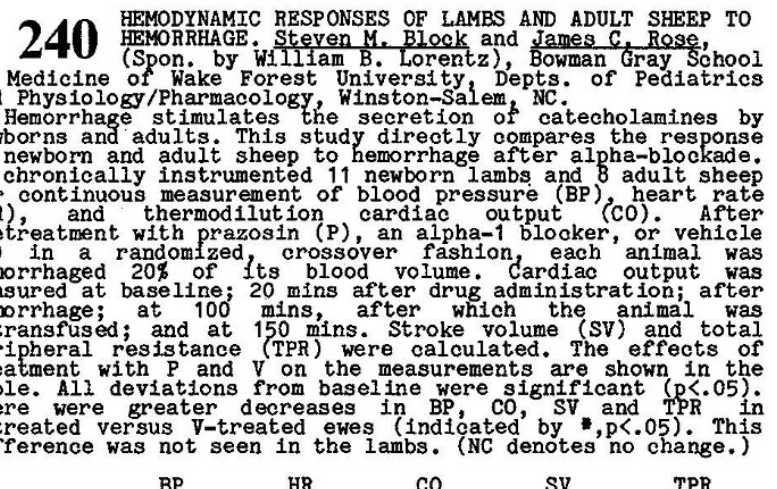

$\begin{array}{lllllll} & & \text { BP } & \text { HR } & \text { CO } & \text { SV } & \text { TPR } \\ \text { Ewes } & \text { V } & \downarrow & \uparrow & \downarrow & \downarrow & \uparrow \\ & \text { P } & \downarrow^{*} & \uparrow & \downarrow & \downarrow & \downarrow^{*} \\ \text { Lambs } & V & \downarrow & \text { NC } & \downarrow & \downarrow & \text { NC } \\ & \text { P } & \downarrow & \text { NC } & \downarrow & \downarrow & \text { NC }\end{array}$

We conclude that catecholamines do not play a major part in (Supported by NIH Grant HD 17644.) 